\title{
Separation of metal laden waste using pulsating air dry material separator
}

\author{
${ }^{1 *}$ Y. He; ${ }^{1}$ C. Duan; ${ }^{1}$ H. Wang; ${ }^{1}$ Y. Zhao; ${ }^{2}$ D. Tao \\ ${ }^{1}$ School of Chemical Engineering and Tech, China Univ. of Mining and Tech, Xuzhou, \\ Jiangsu 221008, China \\ ${ }^{2}$ College of Engineering, University of Kentucky, 40506, USA \\ Received 30 July 2010; $\quad$ revised 4 October 2010; accepted 24 November 2010; $\quad$ available online 1 December 2010
}

\begin{abstract}
Separation of metal laden solid wastes for their recycling utilization using passive pulsed air and active pulsing air classifiers was studied. Laboratory investigation showed that the active pulsing air separator performs more efficiently than the passive pulsed air separator due to the ability to accurately control operating parameters. By studying the difference of drag coefficients of the particles moving through the airflow of varying Reynolds numbers, models of the dynamic particle motion were developed and a computer simulation was prepared. Results of the simulation were reported to predict the observed results with artificial tracing spheres being separated by the laboratory equipment. Two different, real world feed materials were separated with the laboratory scale active pulsing air classifier. The discarded catalyst consisting of precious metal components and sintered magnetic beads was separated with the separation efficiency, of $97.6 \%$. The second real-world feed, electronic scrap crushed to a size of 0.5 to $2 \mathrm{~mm}$, showed a separation efficiency of $92.41 \%$. At the same time, the grade of the recovered concentrate of metals was above $98 \%$.
\end{abstract}

Key word: Dynamic equation; Electronic scraps; Pulsating air; Recycling; Simulation

\section{INTRODUCTION}

Electronic scraps are the fastest growing solid waste in modern society (Winter and Courtney, 2001). They contain significant toxic and hazardous substances and if improperly disposed, are harmful to the environment and health (Nwachukwu et al., 2010). However, recycling and re-utilization of valuable components can be achieved when they are separated effectively (Zhang et al., 1998; Cui and Forssberg, 2003). Wet processing for electronic scraps classification produces washing sludge. Its entrainment of heavy metals and other wastes may cause more serious environmental impacts (Kozlowski et al., 2000; Luga et al., 2001; Igwe et al., 2008; Nwuche et al.,, 2008; Shah et al., 2009). Thermal plasma technology also offers a very promising alternative of electronic waste treatment, but it is still in the laboratory (Tippayawong and Khongkrapan, 2009; Tehrani et al., 2010). Discarded catalysts can be prepared for recycling by chemical processes, such as substance solution, settlement, ion-exchange and

凶*Corresponding Author Email: yqhe@cumt.edu.cn Tel.: +86516 83591099; Fax: +8651683591059 continuous extraction. Then the prepared spongy materials contain platinum, palladium, rhodium, gold, silver and so on (Khanfekr et al., 2009). These spongy materials are difficult to separated from sintered beads by wet separation processes.

Air classification of dry materials with a steadily rising airflow has been used to separate chaff from grain for thousands of years (Joseph, 1979). It is based on the particles' nature of having different terminal velocities in free fall, which in turn, are dependent upon the particles' varying size, shapes and densities (Stessel, 1992; Feng et al., 2009; Wu and He, 2010). Because the terminal velocities of valuable minerals and tailings often overlap, low separation efficiency is obtained when utilizing a conventional straight-pipe air classifier. Therefore, the desired density-dominant separation is not achieved (Jackson et al., 1988). For achieving a density dominant separation, principles of the pulsating air classification and equipment were studied (Senden, 1978; Taub and Peirce, 1983). The passive pulsed air classification was systematically 
researched by Peirce and Stessel of Duke University (Peirce and Wittenberg, 1984; Stessel and Peirce, 1986). In the 1990s, S. Ito of the National Institute of Resource and Environment (NIRE) in Japan studied the performance of the pulsating air classification with a laboratory scale passive pulsed air separator (Ito, 2003). The direction or sectional area of the separation column of passive pulsed air classifiers is changed. This design varies the air velocity, affects air acceleration, and achieves the objective of separating particles by density (Stessel and Peirce, 1986). The methodology of active pulsing air classification was put forward in the early 1990s. The pulsating air generator achieves a better performance than the passive pulsed air separators because the particles receive a new acceleration action in every pulsating period. During the process of air accelerating, turbulence is produced in the active pulsing airflow field. Since the flow pattern is complex, the mechanism of the separation of particles by density is still being investigated.The mail objectives of this work are to study the law of density dominant separation of particles by pulsing air action and to model the dynamic equation of the motion particles. The laboratory separator design and separation experiment began in 2005 and was completed in 2008 in the Ministry Key Lab of Mineral Processing in China University of Mining and Technology. The modelling was successed in 2009.

\section{MATERIALS AND METHODS}

\section{Laboratory Test on Passive Pulsed Air Separator Laboratory Experiment}

Two passive pulsed air separators were used as the experimental settings in this laboratory separation test. "A" represents a design where the amplifications have a ramp cross-section, which gradually introduces a constriction when passing from the bottom to the top of the device. The total length of the separating column is $2000 \mathrm{~mm}$ and the lowest constricting damper is fitted $300 \mathrm{~mm}$ above the column bottom. The damper reduces the column radius by $15 \mathrm{~mm}$ over a vertical distance of $20 \mathrm{~mm}$. "B" represents an alternate design where the constriction is gradually reduced when passing from bottom to top. Otherwise, its geometric parameters are the same as classifier " $A$ ”. The laboratory classifiers are fitted with three or four dampers.

Dampers, whose dimensions are the same as that in the classifier "B", were fitted at the flange joints. Four configurations of the classifier were tested by installing one, two, three and four dampers. These were marked respectively classifiers $\mathrm{C}, \mathrm{D}, \mathrm{E}$ and $\mathrm{F}$. The air classifier marked $G$ is a standard straight-pipe air classifier without any damper.Pieces of aluminum and polyester plastic were mixed as a feed. The pieces had specific gravities of $2.70 \mathrm{~g} / \mathrm{cm}^{3}$ and $1.60 \mathrm{~g} / \mathrm{cm}^{3}$, respectively. The geometric sizes of the aluminum pieces and the polyester plastic pieces were $10 \times 7 \times 2.8 \mathrm{~mm}$ and about $10 \times 10 \times 3 \mathrm{~mm}$. They were weighed and then mixed together and fed into the air classifier. After a given time, the samples were collected at a top collecting plate and from a bottom discharge gate. When the separating time reaches $60 \mathrm{sec}$ there were almost no additional light particles being separated, suggesting that the separating operation completes by this time.

For evaluating the separation effect, the total separation efficiency, $E_{f}$, of light and heavy production is a key index. And, it can be calculated by the formula (Crowe and Peirce, 1988).

$E_{f}=\left[\left(x_{1} / x_{0}\right) \times\left(y_{1} / y_{0}\right)\right]^{1 / 2}$

Where $x_{1}$ is the mass of light material in the product; $x_{o}$ is the total mass of light material in the feed; $y_{1}$ is the mass of heavy material in the product and $y_{0}$ is the total mass of the heavy material in the feed.

Separation experiments of the materials indicate that air classifier $\mathrm{D}$, which has 3 dampers, obtains the highest separation efficiency, followed by classifiers $\mathrm{C}$ and $\mathrm{E}$ shown in Fig.1. The results of separation experiments also indicate that pulsed air classifiers $C$, $\mathrm{D}, \mathrm{E}$ and $\mathrm{F}$, which are fixed with dampers, are more efficient than the standard non pulsating air classifier before 60 seconds separating time. After the separating time exceeds $60 \mathrm{sec}$, nearly no additional light products in air classifiers marked C, D and E are separated. Only in air classifier $\mathrm{F}$ are there a few heavy products reported as light products, so the separation efficiency of air classifier F falls. This phenomenon shows the number of dampers should be within an appropriate extent. Another important criterion for evaluating a good classifier design is that it can maintain high separation efficiency over a wide range of airflow rates. The criterion can be defined as the effective air flow rate over which the separation efficiency is greater than 90 $\%$. Fig. 2 shows the relationship between separation efficiency and separation airflow velocity for different configurations of the classifiers. It indicates that the effective air flow rate for a standard non-pulsating air 


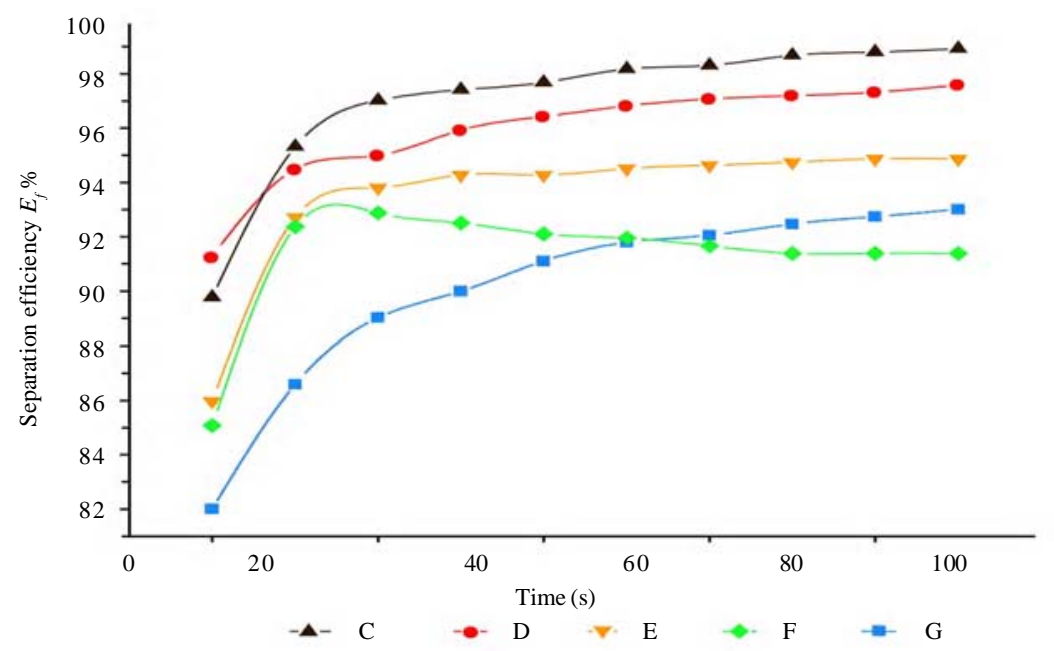

Fig. 1: Efficiency-time curves of the air classifiers

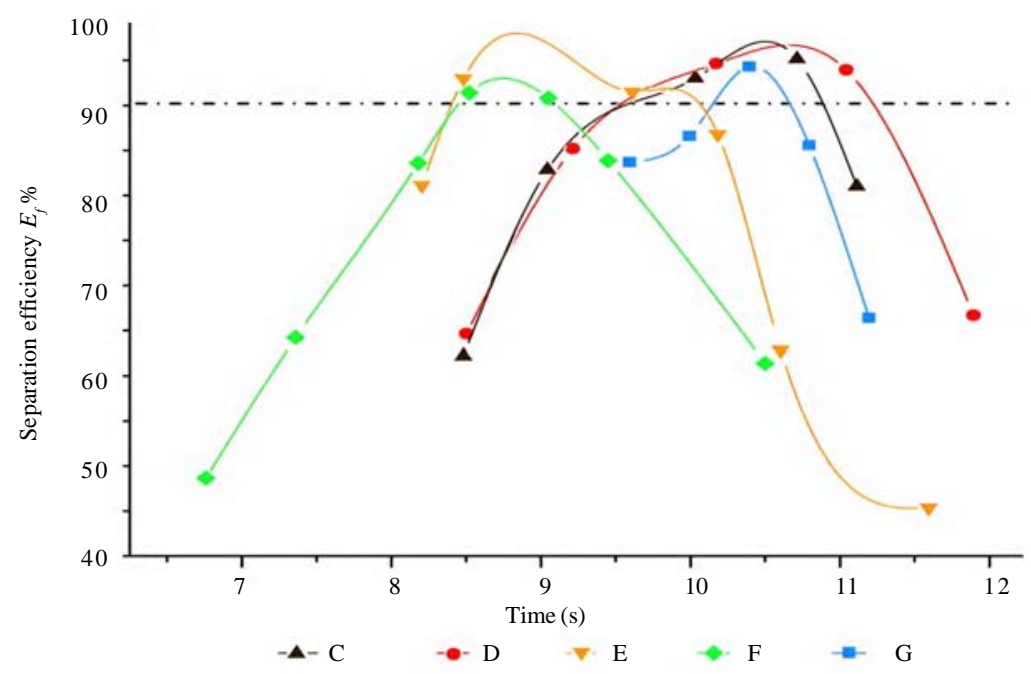

Fig. 2: Effect of air velocity on separation efficiency

classifier is only $0.52 \mathrm{~m} / \mathrm{s}$, while it gets $1 \mathrm{~m} / \mathrm{s}$ or more for the passive pulsed air classifiers fitted with dampers. The effective airflow rate of the air classifier $C$ even reaches $1.72 \mathrm{~m} / \mathrm{s}$. According to this result, it is understood that the effective range of airflow rates of the passive pulsed air classifiers are wider than that of the non-pulsating air classifiers (Duan et al., 2003).

\section{Simulation of the passive pulsed airflow}

For studying the air-stream fields of the passive pulsed air classifiers, simulations were prepared for laboratory experimental tests. It is assumed that the air velocity is symmetrical at the inlet and that the cross air velocity, perpendicular to the direction of inlet airflow, is zero. The boundary condition is no slippage at all sides (all velocity embranchments are zero). Because the airflow is within a low speed range $(<100 \mathrm{~m} /$ s), the flow of air can be regarded as uncompressed flow. The simulation parameters are shown in Table 1. According to Reynolds formula, it was calculated that the Reynolds number, Re, is more than 2000. Hence, the flow in the separating column is turbulent. To study 
Table 1. Parameters for the Air-Stream Field Simulation

\begin{tabular}{lr}
\hline Parameters & Values \\
\hline Airflow velocity at the inlet & $10.0 \mathrm{~m} / \mathrm{s}$ \\
Pressure at the exit & $0 \mathrm{Mpa}$ \\
Air temperature & $20^{\circ} \mathrm{C}$ \\
Air density & $1.205 \mathrm{~kg} / \mathrm{m}^{3}$ \\
Air viscosity & $1.8135 \times 10^{-5} \mathrm{pa} . \mathrm{s}$ \\
\hline
\end{tabular}

the effective regions of the separating column of the two passive air classifiers, the fluid kinetic computation software ANSYS FLOTRAN for airflow pattern analysis was used. The simulated flow fields are used to examine the mechanisms of material separation and to interpret the differences in separating performance between standard and the passive pulsed air classifiers. Only a representative section of the separating column was selected for computer simulations of the airflow fields in the separating area (Wang, 2004; He et al., 2005). In Fig. 3(a) a sharp break of airflow velocity can be observed near the damper, which reaches $18.5 \mathrm{~m} / \mathrm{s}$ in the central part of the column. Dampers cause changes in airflow acceleration. The acceleration effect is highly favorable for achieving the density-dominant separation of particles. The velocity vector distribution of the passive pulsed air classifier " $\mathrm{B}$ " 1 is plotted in Fig. 3(b). Here, it is shown that the effect of the damper on the airflow velocity distribution is significant. The airflow velocity around the damper and at the central part above the damper reaches about $20 \mathrm{~m} / \mathrm{s}$. This is twice the velocity as at the inlet and greater than the corresponding velocity of the passive pulsed air classifier "A". Also, the velocity gradient is steeper than seen in the classifier "A" of Fig. 3(a). The high velocity air stream in the centre of the column takes the light particles out quickly. Therefore, the separating time is shortened. The analysis above for flow patterns indicates that the classifier configuration " $\mathrm{B}$ " is more effective than the classifier "A" in flow acceleration. This is the reason why classifier " $\mathrm{B}$ " was selected as the laboratory separation experiment.

\section{Active Pulsating Air Separation \\ Experimental System}

Typically, as a particle moves through a steady upward air current, forces such as gravity, air buoyancy, drag act on it. Because the fluid flow pattern under study is the active pulsing airflow, the particle will obtain a "new" pulsating air action in every pulsating period, which accelerates the particle. Birkhoff (1960) and Batcelor (1967) considered that the particle not only receives the effect of drag force, but through energy transmission would replace the mass of the fluid, which might resist the particle moving through the flow. This value, a function of the fluid density, the volume and velocity of the particle, is called acceleration effect or "the extra mass force" and can be calculated by Taylor's Theorem of fluid mechanics (Wang and Xiong, 2003). A laboratory scale active pulsing air separator

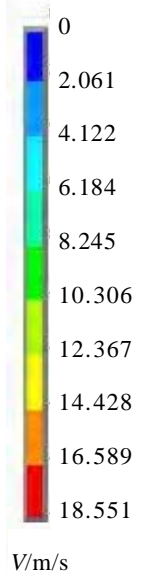

(b)

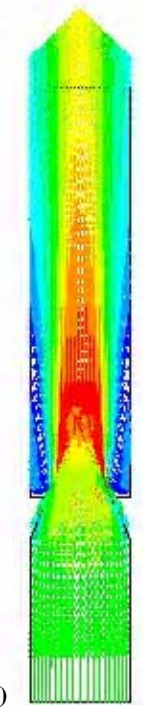

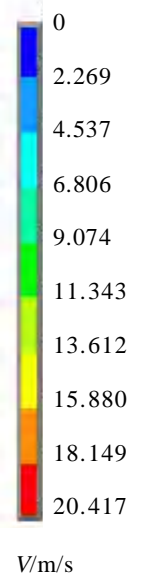

(a)

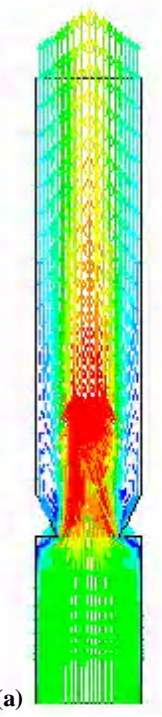

Fig. 3: Velocity vector distributions of the passive pulsed air classifiers (a) “A” classifier (b) "B” classifier 


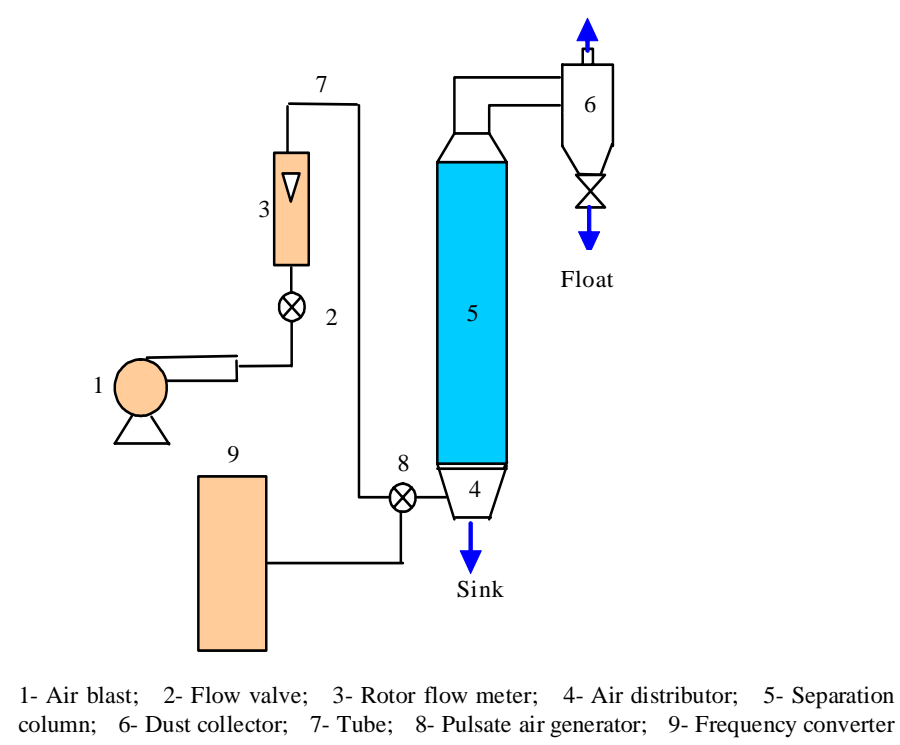

Fig. 4: Experimental system of the active pulsing air separation

and experimental system were developed shown in Fig.4 (He et al., 2005). The separation column with several segments, whose internal diameter is $50 \mathrm{~mm}$ and the length $200 \mathrm{~mm}$, were joined together by flanges to make a $1750 \mathrm{~mm}$ high separator. The active pulsing airflow is produced by the pulsating air generator. The frequency of the pulsating air can be adjusted with a frequency converter.

In the laboratory scale active pulsing air classifier, the rotational speed of the air-valve transmission motor is $1400 \mathrm{r} / \mathrm{min}$ and the reduction ratio of the reducer is 20:1. Therefore, the required time for one cycle of the pulsating air valve should be 0.857 second. Because the active pulsating air generator was modified from a butterfly valve, when it rotates one cycle, two pulsating peaks of air velocity would be produced. To serve as comparison of the computer simulation result and the laboratory separation performance, the pulsating frequencies of 0.857 second and its multiples were applied while in simulation.

\section{Separation Performance to Waste PCBs}

Early research showed that PCBs has the characteristic of selective crushing (Cao et al., 2002). After two-stage crushing, the components analysis indicated that metals are mainly enriched in $-2+1 \mathrm{~mm}$ and $-1+0.5 \mathrm{~mm}$ size fractions. The grades of the metal enrichment in the two size fractions are $45.8 \%$ and 55.7 $\%$ respectively. Though the yield of the crushed product in the fraction $-2+0.5 \mathrm{~mm}$ is $55.38 \%$, the metal distribution rate in the fraction reaches $72.77 \%$. So, it can be concluded that the main metals enrich in the size fraction of $-2+0.5 \mathrm{~mm}$, and this fraction was then taken into the laboratory separation test.

Fig. 5 explains the separation result with the laboratory scale active pulsating air classifier for the crushed waste PCB material. In size fraction $-2+0.5 \mathrm{~mm}$, the separation efficiency of crushed waste PCBs is $92.41 \%$. This is determined by measuring the metal to non-metal components. The grade of the recovered concentrate of metals is above $98 \%$.

\section{Discarded Catalysts Processing}

Catalysts usually contain precious metals, such as platinum, palladium, rhodium, gold and silver. After catalysts lose their activity, they would become the hazardous waste to the environment. However, if these precious metals can be recycled by processing, recycling and reutilization of these discarded catalysts will be achieved. Therefore, by means of substance solution, settlement, ion-exchange and continuous extraction, the precious components can be extracted in sponge materials while the tails leave in sintered beads.

The laboratory active pulsating air separator was used to separate the sponge materials with precious metals from the sintered beads. The feed material was sized by a standard vibrating multi-deck screen set with 
Y. He et al.
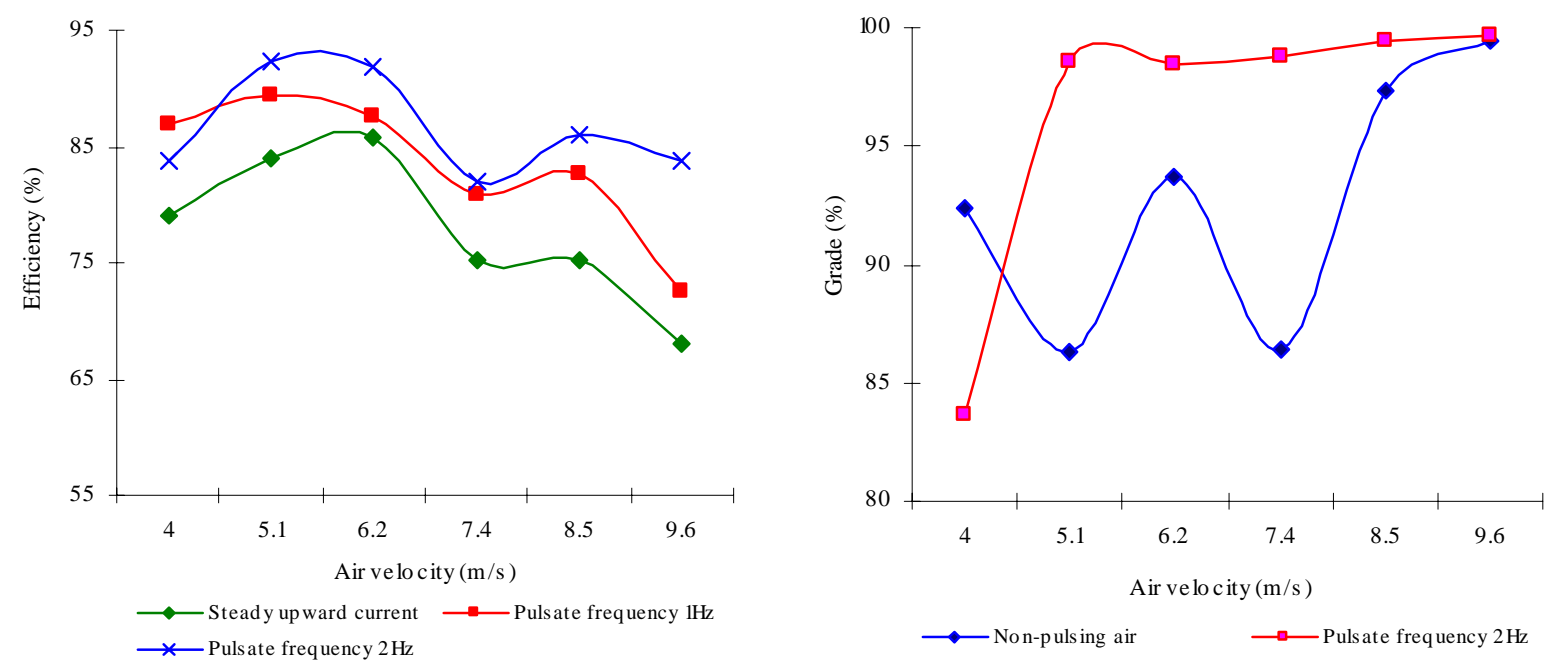

Fig. 5. Separation efficiency of waste PCBs (a) Efficiency curves. (b) Distribution of the metal enrichment

Table 2: Screening results of the discarded catalysts

\begin{tabular}{lccc}
\hline \multirow{2}{*}{ Particle $\mathrm{x}$ Size (mm) } & Weight (\%) & Yields & Ubove screen cum. Yield (\%) \\
\hline $\mathrm{x}>5$ & 0.25 & 0.25 & 100.00 \\
$2<\mathrm{x}<5$ & 49.92 & 50.17 & 99.75 \\
$1<\mathrm{x}<2$ & 43.37 & 93.54 & 49.83 \\
$\mathrm{x}<1$ & 6.46 & 100.00 & 6.46 \\
Total & 100.00 & & \\
\hline
\end{tabular}

Table 3: Separation results of the catalysts with various airflow velocities and a frequency of $7 / 3 \mathrm{~Hz}$

\begin{tabular}{|c|c|c|c|c|c|c|c|c|}
\hline \multirow[t]{2}{*}{ No. } & \multirow{2}{*}{$\begin{array}{l}\text { Vel. } \\
(\mathrm{m} / \mathrm{s})\end{array}$} & \multicolumn{2}{|c|}{ Light product (g) } & \multicolumn{2}{|c|}{ Heavy product (g) } & \multirow{2}{*}{$\begin{array}{c}\text { Sum of light } \\
\text { component } \\
\text { (g) }\end{array}$} & \multirow{2}{*}{$\begin{array}{c}\text { Sum of heavy } \\
\text { component } \\
\text { (g) }\end{array}$} & \multirow{2}{*}{$\begin{array}{l}E_{f} \\
(\%)\end{array}$} \\
\hline & & $\begin{array}{c}\text { Light } \\
\text { component }\end{array}$ & $\begin{array}{c}\text { Heavy } \\
\text { component }\end{array}$ & $\begin{array}{c}\text { Light } \\
\text { component }\end{array}$ & $\begin{array}{c}\text { Heavy } \\
\text { component }\end{array}$ & & & \\
\hline 1 & 5.56 & 23.50 & 1.50 & 0.01 & 13.00 & 23.51 & 14.50 & 94.67 \\
\hline 2 & 5.00 & 23.50 & 1.10 & 0.01 & 13.20 & 23.51 & 14.30 & 96.06 \\
\hline 3 & 4.44 & 23.50 & 1.00 & 0.02 & 13.20 & 23.52 & 14.20 & 96.37 \\
\hline 4 & 3.89 & 23.50 & 0.90 & 0.04 & 13.20 & 23.34 & 14.10 & 96.67 \\
\hline 5 & 3.33 & 22.50 & 0.60 & 0.10 & 13.50 & 22.60 & 14.10 & 97.63 \\
\hline 6 & 2.98 & 22.00 & 0.50 & 0.30 & 13.00 & 22.30 & 13.50 & 97.47 \\
\hline 7 & 2.78 & 21.95 & 0.54 & 0.40 & 13.00 & 22.35 & 13.54 & 97.10 \\
\hline 8 & 2.50 & 21.90 & 0.52 & 0.40 & 13.10 & 22.30 & 13.62 & 97.19 \\
\hline
\end{tabular}

apertures of $5 \mathrm{~mm}, 2 \mathrm{~mm}, 1 \mathrm{~mm}$, and was screened through vibration for $4 \mathrm{~min}$. The size distribution of the materials is shown in Table 2.

In above $457.4 \mathrm{~g}$ feed material, the density of the sponge components is between $0.8 \mathrm{~g} / \mathrm{cm}^{3}$ and $0.9 \mathrm{~g} / \mathrm{cm}^{3}$. The heavy components, which are sintered beads, have density of $1.2 \mathrm{~g} / \mathrm{cm}^{3}$ to $1.3 \mathrm{~g} / \mathrm{cm}^{3}$. From laboratory separation test with the active pulsating air separator, the best separation efficiency was obtained while the frequency of pulsating air was $7 / 3 \mathrm{~Hz}$. Table 3 tells the test result of separating the sponge materials with precious metals from the sintered beads.

Table 3 shows that the best separation efficiency, $97.63 \%$, was achieved with the pulsating frequency of the air being $7 / 3 \mathrm{~Hz}$ and airflow velocity being $3.33 \mathrm{~m} / \mathrm{s}$. In particular, there was a small amount of light component mixed among the sink product, because that is important for concentrating the precious light component. 
Methodology of the Active Pulsating Air Classification

Non-linear Dynamic Equations

As the basic parameter for studying the nature of particles moving through fluid, drag can be expressed as a product of drag coefficient and some relevant factors. However, the factors which influence the drag of particles moving relative to the fluid are complicated and usually they can be described by setting forward an expression of a non-dimension number (Carstens,1952; Karanfilian and Kotas, 1978). To derive the drag coefficient, it is found that in a lower Reynolds number regime $(0<$ Red" 5$)$, the L.Rayleigh curve can be replaced by C.W.O seen approximation perfectly (Zhang and Dong, 2004). While in the fluid of higher Reynolds number, an empirical formula fitted by experimental data is practical, its error being within $\pm 10 \%$. The extra mass force, $F_{E}$, for the acceleration action is shown as below, where, $v_{P}$ is the velocity of the particle, $v_{A}$ is the air velocity, $m_{d f}$ is the mass of the fluid replaced by the particle, and $d$ is the particle's diameter (Brush et al., 1964; Hjelmfelt and Mockros,1967; Mockros and Lai, 1969).

$F_{E}=-\frac{1}{2} m_{d f} \cdot\left(\frac{\partial v_{P}}{\partial t}-\frac{\partial v_{A}}{\partial t}\right)$

From the above description and by force equilibrium, the following equations were derived.

When $0<$ Red"5,

$$
\frac{d v_{P}}{d t}=\frac{1}{\rho_{P}+\frac{1}{2} \rho}\left\{-\rho_{P} g+\frac{3 \rho\left(v_{A}-v_{P}\right)^{2}}{4 d} \cdot\left[\frac{3.6 \times 10^{-4}}{d\left(v_{A}-v_{P}\right)}+\frac{9}{2}\right]+\frac{\rho}{2} \cdot \frac{\partial v_{A}}{\partial t}\right\}
$$

Or, when 0d”Red”2×105,

$$
\begin{aligned}
& \frac{d v_{P}}{d t}=\frac{1}{\rho_{P}+\frac{1}{2} \rho} \times \\
& \left\{-\rho_{P} g+\frac{3 \rho\left(v_{A}-v_{P}\right)^{2}}{4 d} \cdot\left[\frac{3.6 \times 10^{-4}}{d\left(v_{A}-v_{P}\right)}+\frac{6}{1+\sqrt{\frac{d\left(v_{A}-v_{P}\right)}{1.5 \times 10^{-5}}}}+0.4\right]+\frac{\rho}{2} \cdot \frac{\partial v_{A}}{\partial t}\right\}
\end{aligned}
$$

\section{Simulation and Optimization}

For numerical simulation, the imitated materials were used, which were the virtual spherical particles with diameters of $3.5 \mathrm{~mm}, 6 \mathrm{~mm}, 0.94 \mathrm{~mm}$ and densities of $2.4 \mathrm{~g} /$ $\mathrm{cm}^{3}, 1.4 \mathrm{~g} / \mathrm{cm}^{3}$, and $8.9 \mathrm{~g} / \mathrm{cm}^{3}$ respectively. For the imitated materials, the calculation of the terminal settling velocity of the particles should be considered in the situation of the Reynolds number being within the range of the pressure drag. It means that the Newton-Rittinger formula is used to calculate the terminal settling velocity of the particles in the flow of turbulence. Under the environment of normal room temperature, the air density is $1.205 \mathrm{~kg} / \mathrm{m}^{3}$. The terminal velocities $v_{\text {glass }}$ would be $14.312 \mathrm{~m} / \mathrm{s}$, where $v_{\text {plastic }}$ is $14.310 \mathrm{~m} / \mathrm{s}$, and $v_{\text {bronze }}$ equals $14.361 \mathrm{~m} / \mathrm{s}$.

However, the result of the simulation showed a great divergence to the laboratory separation test. The deduced dynamic equations could not reflect the actual response of the particles, and the models were therefore modified. By comparing the results of laboratory study, and by investigating the nature of the pressure drag coefficient, A modification of drag coefficient for particles moving through the pulsating air fluid was provided (Houghton and Carpenter, 2002; Olayiwola and Walzel, 2007). The modification is shown in equation (4) (He et al., 2007).

$$
\begin{aligned}
& \frac{d v_{P}}{d t}=\frac{1}{\rho_{P}+\frac{1}{2} \rho} \times \\
& \left\{\begin{array}{l}
-\rho_{P} g+\frac{3 \rho\left(v_{A}-v_{P}\right)^{2}}{4 d} \cdot\left[\frac{3.6 \times 10^{-4}}{d\left(v_{A}-v_{P}\right)}+\frac{6}{1+\sqrt{\frac{d\left(v_{A}-v_{P}\right)}{1.5 \times 10^{-5}}}}+\frac{2 \times 10^{2}}{\sqrt{\rho_{P}}}\right]+ \\
\frac{\rho}{2} \cdot \frac{\partial v_{A}}{\partial t}
\end{array}\right\}
\end{aligned}
$$

\section{Result of Laboratory Experimental and Simulation}

For investigating the suitability of dynamic equation (4), the Memrecam Ci3 Motion Particle Dynamic Analyzer (MPDA) made by NAC Corporation of Japan, was used for taking photographs and analyzing the digital image data. A specialized image analyzing software, the New Movies, was joined for image computations to obtain the kinematic characteristics of the moving particles in the pulsating air fluid. The photographing speed of the Memrecam Ci3 high-speed camera can be adjusted within a range of 100-2000 frames per second. A portable memory storage device, Iomega Jaz, was used for storing the data. This MPDA was used for comparing the result of laboratory tests and the numerical simulation of moving particles kinetics. As the partial differential equation (4) of the dynamic model is expressed as non-identical functions, 


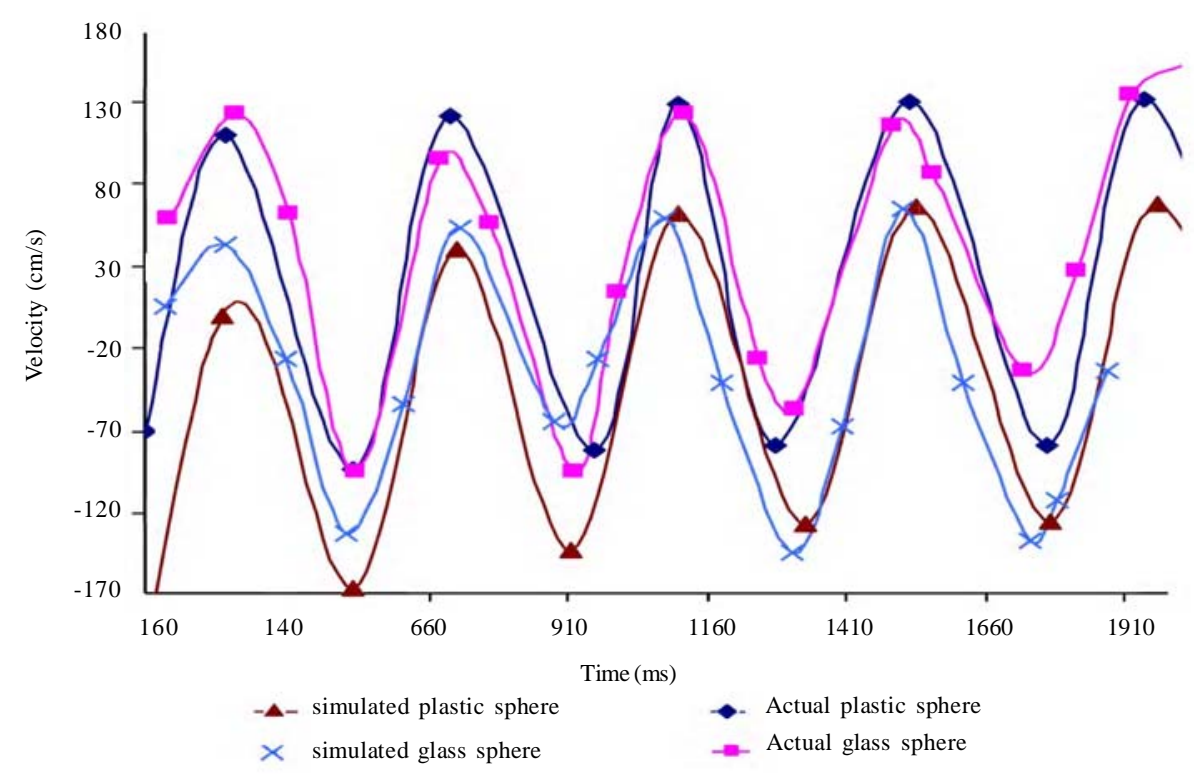

Fig. 6: Comparison of the simulated result and the laboratory test

in which the pulsating air velocity produced by the pulsating air generator is expressed as $v_{\mathrm{A}}=v_{0} \times|1-\cos \alpha|$, where $v_{0}$ is an air velocity while the generator is entirely opened, and $\alpha$ is the rotation angle of the valve. To resolve this problem, a functional operator was developed that reduced the equations to identical form. Then a four or five-rank Runge-Kutta method was applied to solve the resulting set of the equations. In this way a computer simulation was prepared that showed the traces of the particles with different densities and/or diameters, but similar aerodynamic characteristics, as they moved through the turbulent air flow (Zhao et al., 2008; He and Zhao, 2009). These simulated results were compared to the laboratory separation results by using the tracing sphere particles.

The comparison of the numeric simulation and the laboratory test using the tracing spheres is shown in Fig.6. The diameter and density of the spheres in the laboratory test were $4.7 \mathrm{~mm}$ and $1.3 \mathrm{~g} / \mathrm{cm}^{3}$. In the simulation, the velocity of the airflow was set at $9 \mathrm{~m} / \mathrm{s}$, while the velocity of the air in the laboratory test was $9.72 \mathrm{~m} / \mathrm{s}$. The reason that a somewhat larger velocity was used in the laboratory test than in the numeric simulation is to compensate for the pressure head loss and pipe resistance of the laboratory equipment. In Fig. 6, the range of the imitated velocity curve of the plastic spheres varies between $-0.8 \mathrm{~m} / \mathrm{s}$ and $1.2 \mathrm{~m} / \mathrm{s}$, with the mean value near $0.3 \mathrm{~m} / \mathrm{s}$. This result is very close to the MPDA analyzing result, where the photographed positive velocity of the particle is around $1.23 \mathrm{~m} / \mathrm{s}$, which reaches $1.5 \mathrm{~m} / \mathrm{s}$ in the fifth pulsing period, precisely because this velocity peak makes it become a float product. The bottom of the curve was determined by MPDA at $-0.9 \mathrm{~m} / \mathrm{s}$ and this result is almost identical with the results of the simulation. Furthermore, this identical result between simulations and laboratory tests were proven with glass, metal and other spheres.

\section{CONCLUSION}

(1) Passive pulsed air classifiers cause the airflow to accelerate by introducing constricting dampers in certain regions. The accelerating airflow not only makes the particles change their ascending or descending order in the rising and falling process, but also favors the density- dominant separation of particles.

(2) By studying the force balance of particles moving through the active pulsating airflow, a dynamic equation of the motion particles in the active pulsating airflow was developed. Applying a methodology of computational fluid dynamics, the partial differential equations of the dynamic model was solved by numerical computation and simulated. Simulations of the modified dynamic model showed confirming and identical to those results of the laboratory separation tests in an active pulsating air.

(3) Separation of the actual feed material, electronic scrap crushed to a size of 0.5 to $2 \mathrm{~mm}$, shows a separation efficiency of $92.41 \%$. This is determined by 
measuring the metal to non-metal components. The grade of the recovered concentrate of metals is above $98 \%$. Furthermore, to separate the sponge materials with precious metals from the sintered beads of discarded catalysts, the best separation efficiency of $97.63 \%$ was achieved with the pulsating frequency of the air being $7 / 3 \mathrm{~Hz}$ and the airflow velocity being $3.33 \mathrm{~m} / \mathrm{s}$.

\section{ACKNOWLEDGEMENTS}

The authors gratefully acknowledge the financial support provided by the National Natural Science Foundation of China (50574094) and a China Education Ministry Key Laboratory Open Program (CPEUKF0611). Authors also appriciate to a funding from the Science and Technology Innovation Program of Xuzhou, Jiangsu, China (200600242).

\section{REFERENCES}

Batchelor, G. K., (1967). An introduction to fluid dynamics. cambridge Univ. Press, Cambridge, UK.

Birkhoff, G., (1960). Hydrodynamics: A study in logic, fact, and similitude. Revised Ed., Princeton Univ. Press, New York, USA.

Brush, L. M.; Wo, H. W., Yen, B. C., (1964). Accelerated motion of a sphere in a viscous fluid. J. Hydrodynamics, 90 (1), 149-160 (12 pages).

Cao, Y. J.; Wen, X. F.; Zhao, Y. M.; Wang, Q. Q, (2002). Research on selective shredding of wasted printed circuit boards. J. China Univ. Min. Tech., 12 (1), 25-29 (5 pages).

Carstens, M. R., (1952). Accelerated motion of a spherical particle. Transactions of American Geophysics Union, 33 (5), 713-721 (9 pages).

Crowe, P. B.; Peirce, J. J., (1988). Particle density and airclassifier performance. J. Environ. Eng., 114 (2), 282-399 (18 pages).

Cui, J.; Forssberg, E., (2003). Mechanical recycling of waste electric and electronic equipment: A review. J. Hazard Mater., B 99 (3), 243-263 (21 pages).

Duan, C. L.; He, Y. Q.; Wang, H. F.; Zuo, W. R., (2003). Separating mechanism of passive pulsing air classifier. J. China Univ. Min. Tech., 32 (6), 725-728 (4 pages).

Feng, X. D.; Huang, W. L.; Yang, C.; Dang, Z., (2009). Chemical speciation of fine particle bound trace metals. Int. J. Environ. Sci. Tech., 6 (3), 337-346 (10 pages).

He, Y. Q.; Wang, H. F.; Duan, C. L.; Song, S. L.; Zhao, Y. M., (2005). Airflow fields simulation on passive pulsing air classifiers. J. S. Afr. Ins. Min. Metal., 106 (4), 525-531 (7 pages).

He, Y. Q.; Zhao, Y. M.; Duan, C. L.; Zuo, W. R.; He, J. F., (2007). Mechanism of active pulsing air classification and its application to waste PCBs disposal. in: International Symposium on Environmental Science and Technology. Beijing, China 8-11 Nov.

He, Y. Q.; Zhao, Y. M., (2009). Technology of pulsing air separation. Chem. Eng. Industry Press,. Beijing, China.

Hjelmfelt, A. T.; Mockros, L. F., (1967). Stokes flow behavior of an accelerating sphere. J. Eng. Mech., 93 (6), 87-102 (16 pages).
Houghton, E. L.; Carpenter, P. W., (2002). Aerodynamics for Engineering Students. 5th Edition, Butterworth Heinemann, Oxford, MA, USA.

Igwe, J. C.; Abia, A. A.; Ibeh, C. A., (2008). Adsorption kinetics and intraparticulate diffusivities of $\mathrm{Hg}$, $\mathrm{As}$ and $\mathrm{Pb}$ ions on unmodified and thiolated coconut fiber. Int. J. Environ. Sci. Tech., 5 (1), 83-92 (10 pages).

Ito, S., (2003). Development of pneumatic separator using acceleration column. Metallic ore dressing abroad, 23 (5), 38-42 (6 pages).

Jackson, C. R.; Stessel, R. I.; Peirce, J. J., (1988). Passive pulsing air-classifier theory. J. Eng., 114 (1), 106-119 (14 pages).

Joseph, W. L., (1979). Coal Preparation. The American Institute of Mining, Metallurgical, and Petroleum Engineers, INC., New York.

Karanfilian, S. K.; Kotas, T. J., (1978). Drag on a sphere in unsteady motion in a liquid at rest. J. Fluid Mech., 87 (1), 85-96 (12 pages).

Khanfekr, A.; Arzani, K.; Nemati, A.; Hosseini, M., (2009). Production of perovskite catalysts on ceramic monoliths with nanoparticles for dual fuel system automobiles. Int. J. Environ. Sci. Tech., 6 (1), 105-122 (8 pages).

Kozlowski, J.; Mazurck, T.; Czyzyk, H., (2000). The recovering metals and alloys from the electronic scrap. Metal, 54 (11), 645-649 (5 pages).

Luga, A.; Morar, R.; Samuila, A., (2001). Electrostatic separation of metals and plastics from granular industrial wastes. IEE Proc. Sci. Meas. Tech., 148 (2), 47-54 (8 pages).

Mockros, L. F.; Lai, R. Y. S., (1969). Validity of stokes theory for accelerating spheres. J. Eng. Mech., 95 (3), 629-640 (12 pages).

Nwuche, C. O.; Ugoji, E. O., (2008). Effects of heavy metal pollution on the soil microbial activity. Int. J. Environ. Sci. Tech., 5 (3), 409-414 (6 pages).

Nwachukwu, M. A.; Feng, H.; Alinnor, J., (2010). Assessment of heavy metal pollution in soil and their implications within and around mechanic villages. Int. J. Environ. Sci. Tech., 7 (2), 347-358 (12 pages).

Olayiwola, O.; Walzel, P., (2007). Flow pulsation and modified dust surface for process heat transfer intensification. Int. J. Chem. Reactor Eng., 5 (A71), 1-9 (9 pages).

Peirce, J. J.; Wittenberg, N., (1984). Zig-zag configurations and air classifier performance. J. Energ. Eng., 110 (1), 3647 (12 pages).

Senden, M. M. G., (1978). Performance of zig-zag air classifiers at low particle concentrations. Ph. D Dissertation of the Eindhoven Univ. Tech., Eindhoven, Netherlands.

Shah, B. A.; Shah, A. V.; Singh, R. R., (2009). Sorption isotherms and kinetics of chromium uptake from wastewater using natural sorbent material. Int. J. Environ. Sci. Tech., 6 (1), 77-90 (14 pages).

Stessel, R. I.; Peirce, J. J., (1986). Comparing pulsing classifiers for waste-to-energy. J. Energ. Eng., 112 (1), 1-13 (13 pages).

Stessel R. I., (1992). Controlling pulsed incompressible flow. J. Eng., 118 (1), 1-17 (17 pages).

Taub, J. B.; Peirce J. J., (1983). Instabilities in air classification of fuels. J. Energ. Eng., 109 (2), 74-87 (14 pages).

Tehrani, S. M.; Karbassi, A. R.; Monavari, S. M.; Mirbagheri, S. A., (2010). Role of E-shopping management strategy in 
urban environment. Int. J. Environ. Res. 4 (4), 681-690 (10 pages).

Tippayawong, N.; Khongkrapan P., (2009). Development of a laboratory scale air plasma torch and its application to electronic waste treatment. Int. J. Environ. Sci. Tech., 6 (3), 407-414 (8 pages)

Wang, X. F.; Xiong, A. K., (2003). Advanced fluid mechanics. Huazhong Univ. Sci. Tech. Press, Wuhan, China.

Wang, H. F., (2004). Study on the separation mechanism and airflow pattern of pulsed air classifiers. Master's Thesis of China Univ. Min. Tech., Xuzhou, China.

Winter, D.; Courtney, K., (2001). From here to eternity: recycling Hi-tech junk. Waste Age, 32 (3), 186-190 (5 pages).
Wu, J.; He, Ch., (2010). Experimental and modeling investigation of sewage solids sedimentation based on particle size distribution and fractal dimension. Int. J. Environ. Sci. Tech,. 7 (1), 37-46 (10 pages).

Zhang, S.; Forssberg, E.; Menad, N., (1998). Metals recycling from electronic scrap by air table separation- theory and application. In: The TMS Annual Meeting: EPD Congress, San Antonio, USA 16-19 Feb.

Zhang, Z. X.; Dong, Z. N., (2004). Viscous fluid mechanics. Tsinghua Univ. Press, Beijing, China.

Zhao, Y. M.; He, Y. Q.; Duan, C. L.; Zuo, W. R.; Wen, B. F., (2008). Simulation and application of the active pulsing air classification. in: Proceedings of the 11th International Mineral Processing Symposium. Belek-Antalya, Turkey 11-14 Oct.

\section{AUTHOR (S) BIOSKETCHES}

He, Y., MSc, Ph.D. is a professor in the School of Chemical Engineering and Technology, China University of Mining and Technology, Xuzhou, Jiangsu, China. E-mail: yqhe@cumt.edu.cn

Duan, C., MSc, Ph.D. is an associate professor in the School of Chemical Engineering and Technology, China University of Mining and Technology, Xuzhou, Jiangsu, China. E-mail: llaoduan@126.com

Wang, H., MSc, Ph.D. is a lecturer in the School of Chemical Engineering and Technology, China University of Mining and Technology, Xuzhou, Jiangsu, China. E-mail: whfcumt@163.com

Zhao, Y., MSc, Ph.D. is a professor in the School of Environment Science and Spatial Informatics, China University of Mining and Technology, Xuzhou, Jiangsu, China. E-mail: ymzhao@cumt.edu.cn

Tao, D., MSc, Ph.D. is a professor in the Department of Mining and Mineral Resources, University of Kentucky, Lexington, Kentucky, USA. E-mail: dtao@engr.uky.edu

How to cite this article: (Harvard style)

Y. He; C. Duan; H. Wang; Y. Zhao; D. Tao, (2011). Separation of metal laden waste using pulsating air dry material separator. Int. J. Environ. Sci. Tech., 8 (1), 73-82. 